\title{
BDD-Electrolysis of Oxalic Acid in Diluted Acidic Solutions
}

\author{
Tamires F. da Costa, ${ }^{a}$ José E. L. Santos, ${ }^{a}$ Djalma R. da Silva ${ }^{a}$ and \\ Carlos A. Martínez-Huitle ${ }^{\circledR *, a}$ \\ anstituto de Química, Universidade Federal do Rio Grande do Norte, \\ 59072-970 Lagoa Nova-RN, Brazil
}

\begin{abstract}
Boron doped diamond films (BDD) are the most studied electrocatalytic materials and their efficiency for removing organic compounds is attributed to their ability to produce a large amount of hydroxyl radicals by the electrolysis of water. However, some organic compounds are easy to degrade than others, as well as they also interact with BDD surface. Thus, it is necessary to understand the chemical/electrochemical process at the molecular level. In this frame, this work aims to study the electrochemical oxidation (EO) of oxalic acid (OA) at BDD anode, understanding the reaction mechanism, formation of hydroxyl radicals, the effect of supporting electrolyte concentration, and the role of oxidants in solution taking into consideration the cyclic and linear voltammetric measurements. Voltammetric results clearly reveal that a direct electron transfer is achieved as the main mechanistic behavior suffered by OA on BDD surface before oxygen reaction. However, the concentration of sulfates in solution plays an important role in the solvation, diffusion and adsorption species at BDD surface, promoting parallel mechanisms. From the information provided by experimental measurements, the preferential mechanism on BDD surface at low or high overpotential regions was elucidated.
\end{abstract}

Keywords: diamond electrode, oxalic acid, hydroxyl radicals, persulfate

\section{Introduction}

The electrochemical oxidation (EO) of organic compounds is an area of intense research in the field of environmental electrochemistry. ${ }^{1}$ This process can occur by two main mechanisms: direct oxidation at the electrode surface or indirect oxidation mediated by strong oxidants generated at the electrode surface. In the former, pollutants are destroyed directly at anode's surface (M) by direct electron transfer, yielding very poor decontamination. Meanwhile, in the indirect oxidation, the hydroxyl radical $\left({ }^{\circ} \mathrm{OH}\right)$ as well as other strong oxidants (such as persulfate $\left(\mathrm{S}_{2} \mathrm{O}_{8}{ }^{2-}\right)$, active chlorine, ozone, hydrogen peroxide and so on) can be electrochemically produced at anode surface. ${ }^{1}$

In the case of persulfate, ${ }^{2}$ its production is not feasible at all electrodes because it mainly depends on the nature of electrocatalytic material used. It can be produced by direct oxidation of the sulfate ions (equation 1) or by indirect oxidation via ${ }^{\circ} \mathrm{OH}$ (equations 2 and 3 ).

*e-mail: carlosmh@quimica.ufrn.br

$$
\begin{aligned}
& 2 \mathrm{SO}_{4}{ }^{2-} \rightarrow \mathrm{S}_{2} \mathrm{O}_{8}{ }^{2-} \\
& \mathrm{SO}_{4}{ }^{2-}+{ }^{\circ} \mathrm{OH} \rightarrow \mathrm{SO}_{4}{ }^{-}+\mathrm{H}_{2} \mathrm{O} \\
& \mathrm{SO}_{4}{ }^{-\cdot}+\mathrm{SO}_{4}{ }^{-\cdot} \rightarrow \mathrm{S}_{2} \mathrm{O}_{8}{ }^{2-}
\end{aligned}
$$

Among the anodes tested, the boron-doped diamond (BDD) electrode is preferred because it can electrochemically produce ${ }^{\circ} \mathrm{OH}, \mathrm{S}_{2} \mathrm{O}_{8}{ }^{2-}$ and $\mathrm{SO}_{4}{ }^{-{ }^{-2-4}} \cdot{ }^{2-}$ In the case of ${ }^{\circ} \mathrm{OH}$, the weak BDD- ${ }^{\circ} \mathrm{OH}$ interaction and greater $\mathrm{O}_{2}$ overpotential endorse the generation of higher amounts of these reactive oxidants, which mineralize effectively the organic pollutants than other anodes..$^{5-7}$ Meanwhile, the in situ electrogeneration of $\mathrm{S}_{2} \mathrm{O}_{8}{ }^{2-}$ and $\mathrm{SO}_{4}{ }^{--}$using BDD anode has been well-established in recent years. ${ }^{8}$ However, it is necessary to evaluate the experimental conditions in which these strong oxidants are efficiently produced because the reactions suggest competitive mechanisms between hydroxyl radicals and persulfate.

For this reason, we present significant electrochemical evidences about the influence of supporting electrolyte concentration as well as applied current density on the production of $\mathrm{S}_{2} \mathrm{O}_{8}{ }^{2-}$ when BDD electrode is used. Note that this behavior was also studied, for the first time, during the EO of a model organic compound, such as, 
oxalic acid (OA). The oxidation of OA has been well investigated experimentally and has been extensively discussed by Comninellis and co-workers ${ }^{5}$ and De Battisti and co-workers..$^{910}$ On the basis of experimental evidence, Comninellis and co-workers ${ }^{5}$ proposed the following mechanism:

$$
\begin{aligned}
& \mathrm{H}_{2} \mathrm{O} \rightarrow{ }^{\cdot} \mathrm{OH}+\mathrm{H}^{+}+\mathrm{e}^{-} \\
& \mathrm{C}_{2} \mathrm{O}_{4} \mathrm{H}_{2}+{ }^{\cdot} \mathrm{OH} \rightarrow \mathrm{C}_{2} \mathrm{O}_{4} \mathrm{H}^{-}+\mathrm{H}_{2} \mathrm{O} \\
& \mathrm{C}_{2} \mathrm{O}_{4} \mathrm{H}^{-} \rightarrow \mathrm{COOH}+\mathrm{CO}_{2} \\
& \mathrm{COOH}+{ }^{\circ} \mathrm{OH} \rightarrow \mathrm{CO}_{2}+\mathrm{H}_{2} \mathrm{O}
\end{aligned}
$$

The standard equilibrium potential of equation 4 is $2.38 \mathrm{~V} v s$. reversible hydrogen electrode (RHE) (2.13 V vs. saturated calomel electrode (SCE)). ${ }^{5,11}$ It can trigger a number of incineration reactions, which set in near this potential. However, the production of persulfate was always considered unimportant during the production of ${ }^{\circ} \mathrm{OH}$, even when the concentration of sulfate in solution was higher. Although, the original results reported here demonstrate that it is not completely insignificant.

\section{Experimental}

OA was purchased from J.T. Baker and used without further purification. $\mathrm{H}_{2} \mathrm{SO}_{4}$ was used as supporting electrolyte (in diluted conditions) for $0.01,0.02$ and $0.03 \mathrm{M}$ of OA concentrations. All solutions were prepared with high-purity water obtained from a Millipore Milli-Q system with resistivity $>18 \mathrm{M} \Omega \mathrm{cm}$ at $25^{\circ} \mathrm{C}$. Cyclic voltammetry analyses were performed at room temperature $\left(25^{\circ} \mathrm{C}\right)$ with a Metrohm AUTOLAB potentiostat model PGSTAT302N. The three-electrode cell was constituted by an SCE as reference electrode, $\mathrm{Pt}$ wire as the counter electrode and BDD as working electrode with an exposed geometric area of $0.8 \mathrm{~cm}^{2}$. The working electrode was subjected to repetitive cycles from 0 to $2.4 \mathrm{~V}$ at the scan rate of $50 \mathrm{mV} \mathrm{s}^{-1}$, by using cyclic voltammetry, in presence or in absence of $\mathrm{OA}$ in diluted solution of $\mathrm{H}_{2} \mathrm{SO}_{4}$ as supporting electrolyte. Quasi-steady polarization curves were also carried out at a scan rate of $10 \mathrm{mV} \mathrm{s}^{-1}$ and with a $2.44 \mathrm{mV}$ step potential under similar experimental conditions.

\section{Results and Discussion}

\section{Electrochemical measurements}

Prior to understand the persulfate reactions and on the basis of the introductory considerations regarding the electrocatalytic nature of BDD anode, electrochemical measurements were performed to increase the understanding of mechanisms related to the supporting electrolyte oxidation as well as the model organic compound oxidation by involving the participation of oxygen reactive species, like hydroxyl radicals.

Cyclic voltammograms of solutions in absence (only supporting electrolyte) and in presence of OA at different concentrations (from 0.01 to $0.03 \mathrm{M}$ ) in diluted acidic solutions $\left(\mathrm{H}_{2} \mathrm{SO}_{4}\right.$ at 0.0001 and $\left.0.00001 \mathrm{M}\right)$ were performed and showed in Figure 1. It is important to remark that, diluted solutions of $\mathrm{H}_{2} \mathrm{SO}_{4}$ were used to increase the importance of water molecules in the reaction cage to understand, electrochemically, the production and the role of hydroxyl radicals on the OA electrooxidation, as well as the comprehension of solvation effects, already considered on the theoretical calculations in the literature. ${ }^{11}$ In the absence of OA in solution, no significant signals were observed and a typical cyclic voltammetric curve for a diamond electrode in acidic media with lower background current (less than $1 \mu \mathrm{A}$ ), as well as the oxygen evolution potential at about $+2.18 \mathrm{~V} v s$. SCE, ${ }^{11}$ were registered. Meanwhile, as can be seen in Figure 1, the increase in OA concentration leads to the appearance of two oxidation waves by using different supporting electrolyte concentrations. The first voltammetric signal is observed before the discharge of water $(+1.3 \mathrm{~V} v s$. $\mathrm{SCE})$ and a very broad peak at $+2.06 \mathrm{~V}$ was registered (see insets in Figures 1a and 1b). The signal is dependent on the supporting electrolyte concentration, considering that its concentration is different in both cases $(0.0001$ and $0.00001 \mathrm{M}$ ), because the solvation effect plays an important role on the interaction of OA molecules and BDD surface. ${ }^{9-11}$

In the former case, the oxidation process does not imply transfer of an oxygen atom, in other words, it could be a phenomenon related to a direct electron transfer to the BDD surface: ${ }^{12}$

$\mathrm{C}_{2} \mathrm{O}_{4} \mathrm{H}_{2} \rightarrow 2 \mathrm{CO}_{2}+2 \mathrm{H}^{+}+2 \mathrm{e}^{-}$

However, the existence of a slight signal at higher currents can suggest the participation of reactive oxygen species (ROS, e.g., hydroxyl radicals ( $\left.{ }^{\circ} \mathrm{OH}\right)$ ) electrochemically generated at BDD surface: ${ }^{5,10}$

$$
\mathrm{C}_{2} \mathrm{O}_{4} \mathrm{H}_{2}+\cdot \mathrm{OH} \rightarrow \mathrm{CO}_{2}+\mathrm{H}_{2} \mathrm{O}
$$

In this way, the oxidation could take place by a particular interaction of OA molecule towards BDD surface involving the co-existence of mechanisms that include the surface reaction between ${ }^{\circ} \mathrm{OH}$ and adsorbed/non-adsorbed $\mathrm{OA}$ (in its ion $\left(\mathrm{HC}_{2} \mathrm{O}_{4}^{-}\right)$or radical $\left(\mathrm{HC}_{2} \mathrm{O}_{4}{ }^{-}\right)$form): ${ }^{9,10,13}$ 

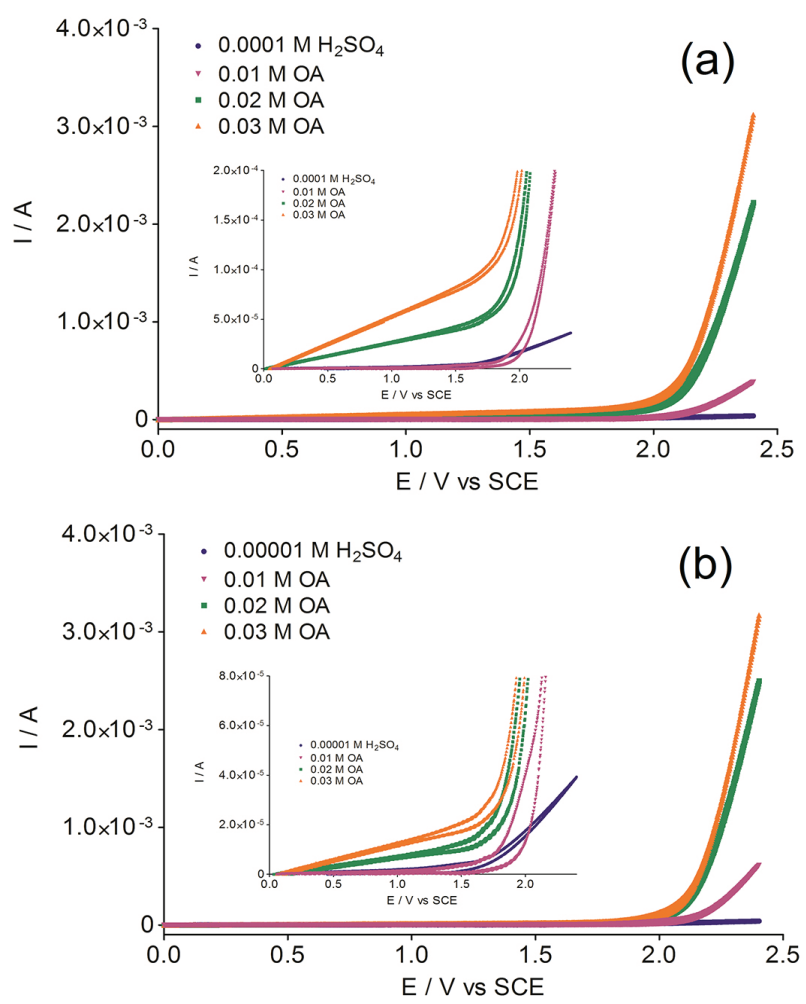

Figure 1. Cyclic voltammograms of $\mathrm{OA}$ with $\mathrm{BDD}$ electrode at different concentrations by using diluted $\mathrm{H}_{2} \mathrm{SO}_{4}$ solutions: (a) 0.0001 and (b) $0.00001 \mathrm{M}$, as supporting electrolyte, at scan rate of $10 \mathrm{mV} \mathrm{s}^{-1}$. Inset: magnification of voltammograms very close to oxygen evolution reaction (o.e.r.).

$$
\begin{aligned}
& 2 \mathrm{M}-\cdot \mathrm{OH}+\mathrm{HC}_{2} \mathrm{O}_{4}^{-}+\mathrm{H}^{+} \rightarrow \mathrm{M}+2 \mathrm{CO}_{2}+2 \mathrm{H}_{2} \mathrm{O} \\
& \mathrm{M}-\cdot \mathrm{OH}+\mathrm{M}-\mathrm{HC}_{2} \mathrm{O}_{4}^{-} \rightarrow 2 \mathrm{M}+2 \mathrm{CO}_{2}+\mathrm{H}_{2} \mathrm{O}
\end{aligned}
$$

However, as indicated by Chen and Shyu ${ }^{14}$ and Buonaugurio et al. ${ }^{15}$ various conformers of the OA can be achieved; and consequently, the mechanism can be diverse.

Based on these assumptions, OA oxidation seems to be a complex group of reactions before and after oxygen evolution. As indicated above, a direct electron transfer of OA molecule with BDD surface is achieved, but an indirect oxidation by ${ }^{\circ} \mathrm{OH}$ radical can also be attained.

In order to obtain more information about the electrochemical oxidation of OA at BDD surface, polarization curves were obtained in absence $\left(\mathrm{H}_{2} \mathrm{SO}_{4}\right.$ as supporting electrolyte) and in presence of $\mathrm{OA}$ at different concentrations (from 0.01 to $0.03 \mathrm{M}$ ) in diluted acidic solutions (0.0001 and $0.00001 \mathrm{M}$ of $\mathrm{H}_{2} \mathrm{SO}_{4}$ ).

Figure 2 shows linear polarization curves in absence and in presence of $\mathrm{OA}$ at $25^{\circ} \mathrm{C}$ with $\mathrm{BDD}$ electrode at a scan rate of $10 \mathrm{mV} \mathrm{s}^{-1}$. The $\mathrm{H}_{2} \mathrm{SO}_{4}$ curve (blue circle) shows that oxygen evolution potential is about $+2.1 \mathrm{~V} v s$. SCE. This means that this anode has high oxygen evolution overpotential and consequently is a poor electrocatalyst for the oxygen evolution reaction (o.e.r.): ${ }^{16-18}$
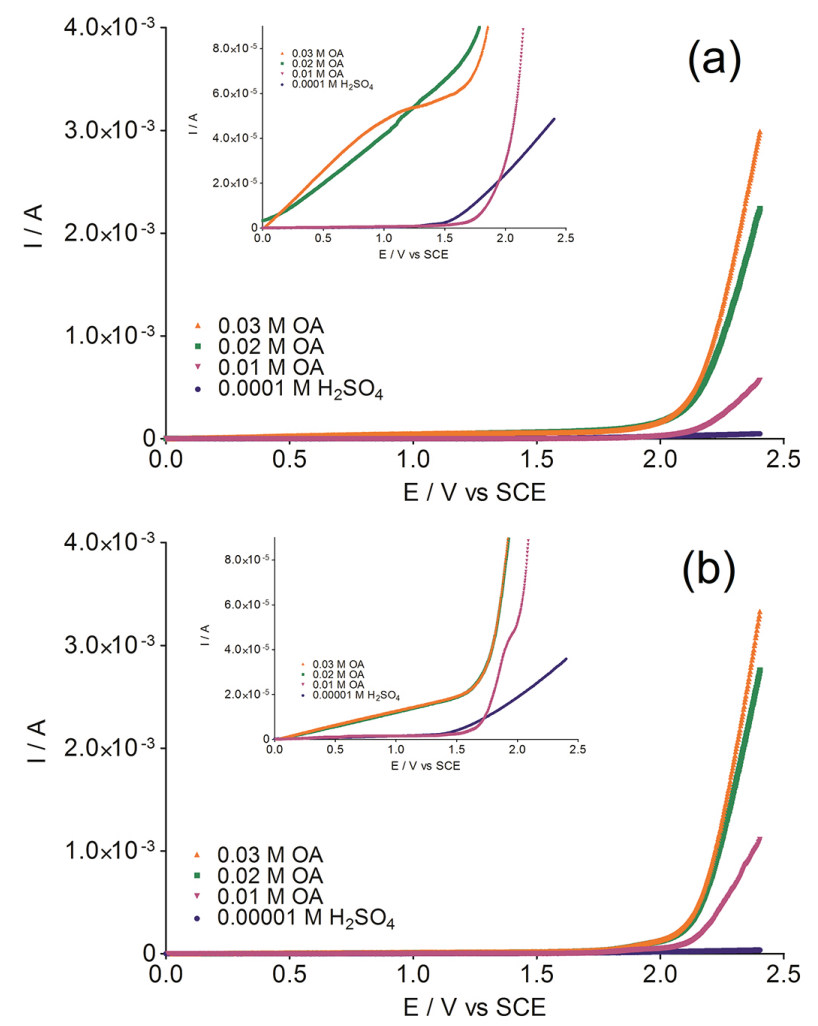

Figure 2. Polarization curves for a BDD electrode registered at different concentrations of $\mathrm{OA}$ by using diluted $\mathrm{H}_{2} \mathrm{SO}_{4}$ solutions: (a) 0.0001 and (b) $0.00001 \mathrm{M}$, as supporting electrolyte. Insets: zoom of polarization curves.

$\cdot \mathrm{OH} \rightarrow{ }^{1 / 2} \mathrm{O}_{2}+\mathrm{H}^{+}+\mathrm{e}^{-}$

The electrochemical behavior of OA registered at quasi-steady polarization curves indicates that the currents due to OA oxidation are shifted to potentials before the oxygen evolution and the features of $\mathrm{i} / \mathrm{E}$ curves are affected by the presence of OA. ${ }^{10}$

The onset of the OA oxidation is located in the potential range 1.53-1.63 $\mathrm{V}$, much lower with respect to the threshold of about $2.1 \mathrm{~V}$ at which the oxygen evolution starts. These results showed that $\mathrm{OA}$ is electroactive at BDD material, and a partial oxidation takes place directly at BDD surface before the o.e.r. onset. ${ }^{10}$ As shown in the insets of Figures $2 a$ and $2 b$, the increase on the current is dependent on the OA concentration as well as the supporting electrolyte concentration. This result clearly demonstrates that the solvation phenomena are participating during the interactions of OA molecules with BDD surface..$^{15}$ Nevertheless, this interaction is more evident when a diluted acidic solution is used $(0.00001 \mathrm{M})$, in other words, when water molecules are predominantly existing in the medium. This behavior is related to the reaction steps followed during the OA electrooxidation. Assuming that only water molecules 
are present in solution, direct (reaction 8) and indirect (reactions 4 to 7) electrochemical oxidations can be attained. Meanwhile, when the concentration of $\mathrm{H}_{2} \mathrm{SO}_{4}$ increases in solution, additional effects could be attained on BDD surface, contributing indirectly to the oxidation of OA. This occurrence can be verified from the analysis of polarization curves and Tafel plots for different concentrations of supporting electrolyte as well as when $\mathrm{OA}$ is present in solution.

$\mathrm{E} / \mathrm{I}$ plots at BDD electrode at different concentrations of $\mathrm{H}_{2} \mathrm{SO}_{4}$ are shown in Figure 3. As can be observed, o.e.r. is the main process at lower concentrations of $\mathrm{H}_{2} \mathrm{SO}_{4}$, and it is achieved at higher potentials (> 1.8 V). However, this reaction seems to be strongly hindered at higher $\mathrm{H}_{2} \mathrm{SO}_{4}$ concentration, and the signal of polarization curve at about $2.1 \mathrm{~V}$, at higher currents, underlines the complex set of electrochemical reactions taking place at the diamond surfaces, involving most probably the o.e.r. and persulfate production. ${ }^{19}$ From the experimental polarization curves, the Tafel lines were plotted in the overpotential region $>1.6 \mathrm{~V}$ (inset in Figure 3). It can be seen that, the Tafel plot modifies its slope according to the low $(<2.0 \mathrm{~V})$ or high overpotential region $(>2.0 \mathrm{~V})$, principally at high supporting electrolyte concentrations $(0.001$ and $0.01 \mathrm{M})$. These curves deviate strongly from linearity. Thus, no unique slope can be attributed to these curves due to the electrochemical reactions that take place. ${ }^{20}$ In fact, Tafel slopes about 0.640 and $0.495 \mathrm{~V} \mathrm{decade}^{-1}$ for acidic solutions of 0.001 and $0.01 \mathrm{M}$ were estimated, respectively, at low overpotential region. Meanwhile, 0.902 and $0.575 \mathrm{~V} \mathrm{decade}^{-1}$ in the high overpotential region were obtained for supporting electrolyte solutions of 0.001 and $0.01 \mathrm{M}$, respectively. Two distinct linearity regions can be attributed to the electrochemical reactions on the layer of BDD related to sulfate ions in solution, when these are in the Nernst layer, which are transformed by oxidation process to persulfate..$^{21,22}$

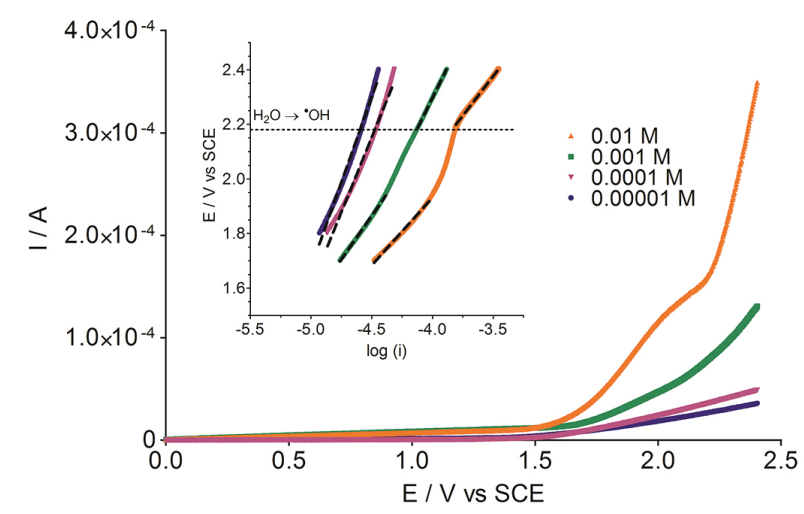

Figure 3. Polarization curves registered at BDD electrode by using different diluted acidic solutions. Inset: data in terms of Tafel plots.
On the contrary, the Tafel curves at lower supporting electrolyte concentrations have great linearity, but unusually high slopes were achieved. Such abnormally high Tafel slopes may result from the presence of surface redox couples/surface functional groups on BDD. ${ }^{20}$ In fact, the lower solution conductivity as well as the functional groups at electrode surface can act as a barrier for o.e.r. leading to both high Tafel slope and high overpotential for oxygen evolution. ${ }^{23-27}$ Also, the hypothesis of the effect of the gas bubbles at the electrode surface should be considered. In fact, the investigation of the Tafel slope of gas-evolving reactions is difficult due to the formation of gas bubbles at the electrode surface, ${ }^{28,29}$ because the nucleation of bubbles depends on the saturation degree of the gas in the liquid, which is controlled by the mass transfer (it is also dependent on the conductivity of solution) and the current density. ${ }^{23-29}$

According to the Figure 3, significant linearity is observed at much diluted acidic solution $(0.00001 \mathrm{M}$ of $\mathrm{H}_{2} \mathrm{SO}_{4}$ ), indicating the prevalence of electrochemical reactions related to reactive oxygen species (e.g., hydroxyl radicals). ${ }^{20}$ Comparing both diluted $\mathrm{H}_{2} \mathrm{SO}_{4}$ concentrations, 0.0001 and $0.00001 \mathrm{M}$ (see inset in Figure 3), similar Tafel slopes were obtained: 1.096 and $1.202 \mathrm{~V} \mathrm{decade}^{-1}$, respectively, but the increase on the concentration of sulfate ions in solution starts to influence the phenomena at BDD surface. Based on these results, those solutions were used as supporting electrolytes for obtaining experimental data regarding the electrochemical oxidation of $\mathrm{OA}$ in order to avoid the interactions with other chemical species in solution, principally the interference due to the electrosynthesis of persulfate. ${ }^{19,22,30,31}$

Figure 4 shows the Tafel plots obtained from the polarization curves (see Figure 2) for the electrochemical oxidation of $\mathrm{OA}$ at different concentrations by using as supporting electrolyte, diluted acidic solutions $(0.0001 \mathrm{M}$ (Figure 4a) and 0.00001 M (Figure 4b)).

As can be seen in Figure 4, the linearity of the Tafel plots, at different regions, is related to the chemical/ electrochemical reactions ${ }^{5,10,13}$ (solvation, diffusion, adsorption, electron transfer, $\mathrm{H}_{2} \mathrm{SO}_{4}$ oxidation, ${ }^{\circ} \mathrm{OH}$ radical production, OA oxidation, ${ }^{30,31}$ etc.) achieved in the proximity of the BDD surface at different potentials, which are dependent on the $\mathrm{OA}$ and supporting electrolyte concentrations in solution.

As showed in Figure 4, two distinct linearity regions can be found in $\mathrm{E} / \log$ i plots, prior to the complete o.e.r, in the presence of OA in solution. In both cases, the OA concentration prevails over sulfate ions concentration in solution. ${ }^{30}$ However, when supporting electrolyte has a concentration about $0.0001 \mathrm{M}$ (Figure 4a), the conductivity of solution is major than that at $0.00001 \mathrm{M} \mathrm{H}_{2} \mathrm{SO}_{4}$, then, 

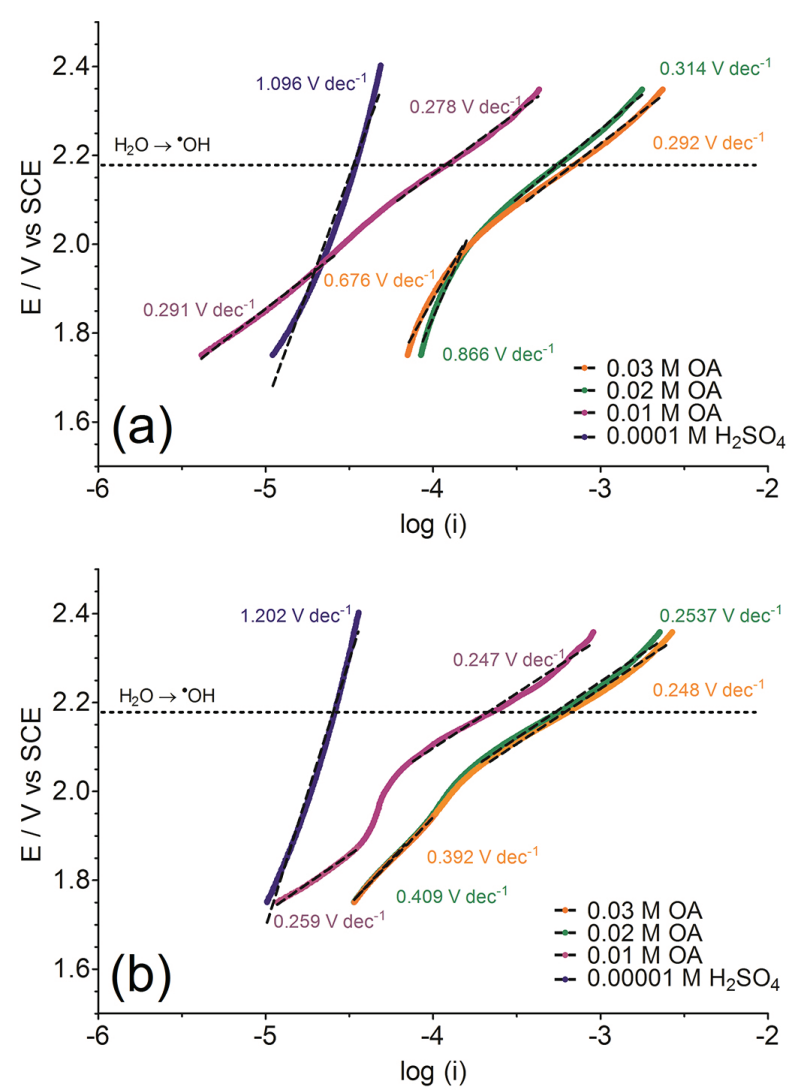

Figure 4. Tafel plots of EO of OA at different concentrations by using diluted $\mathrm{H}_{2} \mathrm{SO}_{4}$ solutions: (a) 0.0001 and (b) $0.00001 \mathrm{M}$, as supporting electrolyte. Both graphics were divided at lower and higher overpotential regions from the potential of hydroxyl radicals formation. ${ }^{5,20}$

the predominance of sulfate ion in solution is evident ( $>10$ folds), and it contributes to promote the persulfate formation. ${ }^{32-34}$ This effect was already studied by Davis et al. ${ }^{19}$ who indicated that the most easily oxidized species is $\mathrm{SO}_{4}{ }^{2-}$, and the most difficult to oxidize species is $\mathrm{H}_{2} \mathrm{SO}_{4}$ (no dissociated molecules). Meanwhile, for $\mathrm{H}_{2} \mathrm{O}$ oxidation, electrode potentials above ca. $2 \mathrm{~V}$ are required for measurable rates of water oxidation. Conversely, the electrogeneration of persulfate is incomplete at lowest $\mathrm{H}_{2} \mathrm{SO}_{4}$ concentration, when it is used as supporting electrolyte, because the water molecules are predominant in solution and, consequently, a greater catalytic activity for water oxidation versus sulfate species oxidation can likely be attributed to BDD electrode. ${ }^{34}$

On the basis of the results obtained here, the possibility of co-existing mechanisms at BDD surfaces is feasible, depending on the hydroxyl radical formation. For the first linear segment at the Tafel curves in the Figure 4a (at low overpotential region $(<2.0 \mathrm{~V})$ ), the rate determining step is rather the persulfate formation, ${ }^{22}$ in competition with the surface reaction with adsorbed OA. ${ }^{10,35}$ After that, reactions between ${ }^{\circ} \mathrm{OH}$ (when it is formed) and $\mathrm{OA}$ are attained at high overpotential region $(>2.0 \mathrm{~V})$. This is confirmed when the effects of solutions of 0.01 and $0.02 \mathrm{M}$ of OA in $0.0001 \mathrm{M}$ $\mathrm{H}_{2} \mathrm{SO}_{4}$ are compared. In the former, very similar slope is achieved at both segments of Tafel curve, indicating that the determining step is the oxidation of sulfate ion with a weak interaction of OA towards the surface at low overpotential region. Nevertheless, the hydroxyl radical formation, followed by the bimolecular surface reaction between ${ }^{\circ} \mathrm{OH}$ and adsorbed OA, is the main behavior. In fact, similar Tafel slopes were determined at all OA concentrations at high overpotential region $(>2.0 \mathrm{~V})$ and a reaction order of about 1.7, with respect to OA concentration, was obtained. This outcome confirms that the electrochemical reactions depend on the participation of the reactive oxygen species formed at those potentials. Conversely, when an increase on the OA concentration is attained, the rate determining step is the direct oxidation of OA at BDD surface, as can be seen in Tafel slopes in Figure 4a, increasing the energy of activation ${ }^{5}$ with a reaction order of about 2.53 , revealing a significant surface activity toward OA oxidation.

Analyzing the behavior showed at Tafel curves when much lower diluted acidic solution was used as supporting electrolyte (0.00001 M, see Figure 4b), two interesting features can be observed. Firstly, the Tafel slopes at high overpotential region $(>2.0 \mathrm{~V})$ are very similar between them (ca. $0.250 \mathrm{~V} \mathrm{dec}^{-1}$ ) and these values are very close to those slope values estimated when $0.0001 \mathrm{M} \mathrm{H}_{2} \mathrm{SO}_{4}$ was used, indicating that the reactions are dependent on the water oxidation intermediates ( $\mathrm{OH}$ radicals). Secondly, when the sulfate concentration is decreased on 10-folds (from 0.0001 to $0.00001 \mathrm{M}$ ) and the OA molecules in solution are increased by 1000 -folds with respect to the sulfate ions (0.01 M OA/0.00001 $\left.\mathrm{M} \mathrm{H}_{2} \mathrm{SO}_{4}\right)$, the effect observed at low overpotential region $(<2.0 \mathrm{~V})$ is clearly due to the OA on BDD surface (direct oxidation). From Tafel plot data (Figure 4b), a reaction order of about 0.79 could be estimated, revealing a significant surface activity toward OA oxidation. In summary, under potentiostatic conditions, the oxidation of OA corresponds to the co-existence of a possible direct electron-transfer reaction, at a potential below that for water discharge, and the participation of 'OH radicals at higher potential, when the formation of persulfate is not promoted. These outcomes will be confirmed by theoretical calculations, considering the nature of OA-chemical structure, solvation and formation of ${ }^{\circ} \mathrm{OH}$ radicals. ${ }^{11}$

According to the computational estimations, the energy of activation was about $0.25 \mathrm{eV}$ for both calculations performed by Ignaczak et al. ${ }^{11}$ The values differ by about $0.15 \mathrm{eV}$ for the two implicit solvent models used. This implies that the onset potential for incineration reactions that are triggered by ${ }^{\circ} \mathrm{OH}$ should be a little below $2.38 \mathrm{~V}$ 
RHE (or ca. $2.13 \mathrm{~V} v$ s. SCE), ${ }^{5,11}$ the exact value depending on the rate of the subsequent reactions. In fact, these assertions are in agreement with the electrochemical measurements obtained at both diluted acidic solutions in absence (the importance of solvation effects plays a significant role on the formation of hydroxyl radicals as well as persulfate on BDD electrode) or in presence of OA where the direct oxidation can be attained on BDD surface at low overpotential region. Restricting now our results to the reactions related to direct electron transfer or OA oxidation at BDD surface, important attempts should be considered, such as the conformational changes of OA molecule in solution, bonds breaking and the interaction of hydroxyl radicals as well as their relationship with the electrochemical behaviors attained. Also, Ignaczak et al. ${ }^{11}$ indicated that the incineration of $\mathrm{OA}$ by ${ }^{\circ} \mathrm{OH}$ is a reaction highly exothermic. This suggests a fast reaction rate, and demonstrates the big advantage of generating ${ }^{\circ} \mathrm{OH}$ on BDD at high anodic potentials. In fact, it is in agreement with the electrochemical measurements reported in Figures 2 and 4 because the interaction of OA with BDD surface at low overpotential region is thermodynamically favored, but the participation of hydroxyl radicals is also attained when the anodic potential is increased. However, the dynamism of the interaction depends on the change in the shape of a molecule that is often induced by environmental factors (temperature, $\mathrm{pH}$, voltage, ion concentration, phosphorylation, or the binding of a ligand).

In the theoretical works of Chen and Shyu ${ }^{14}$ and Buonaugurio et al. ${ }^{15}$ various conformers of the $\mathrm{OA}\left(\mathrm{H}_{2} \mathrm{C}_{2} \mathrm{O}_{4}\right)$ were explored. In all three species $\left(\mathrm{H}_{2} \mathrm{C}_{2} \mathrm{O}_{4}, \mathrm{HC}_{2} \mathrm{O}_{4}\right.$ and $\mathrm{COOH})$, the cis and trans conformations are separated by energy barriers by about $0.4-0.5 \mathrm{eV}$. Of course there can be other barriers associated with bond breaking in the reactions, to which we shall now turn our attention. It is also confirmed by the electrochemical measurements because the extra energy or the energy necessary for breaking $\mathrm{C}-\mathrm{C}$ bond could be obtained from the direct interaction of $\mathrm{OA}$ with BDD surface, however, this hypothesis is not feasible. An important hindrance due to the carboxyl OA groups should be expected, being the interaction of $-\mathrm{COO}^{-}$or $-\mathrm{COOH}$ with BDD surface, the most achievable.

As already mentioned by Ignaczak et al., ${ }^{11}$ the total energy gain is about $-7 \mathrm{eV}$, which is extremely high for an electrochemically triggered reaction in solution. Then, these reactions can be attained at high overpotential region $(>2 \mathrm{~V}$, see Figure 4), or very close to the formation of hydroxyl radicals potential. In the latter case, Tafel plots confirm that an electrochemical reaction, possibly reaction 4 , starts very close to the theoretical potential of water discharge (e.g., $\cdot \mathrm{OH}$ radicals production), which is supported by the same values of Tafel slopes estimated at different concentrations of OA in solution. Then, water electrolysis is attained and, consequently, higher concentration of ${ }^{\circ} \mathrm{OH}$ radicals is produced at BDD surface; after that, this concentration decreases rapidly because these reactive oxygen species are very reactive. Then, these outcomes (experimental and theoretical-conformational changes) are in total agreement with the calculations about the generation of ${ }^{\circ} \mathrm{OH}$ radicals because the energies confirm that the onset potential for incineration reactions that are triggered by ${ }^{\circ} \mathrm{OH}$ should be a little below $2.38 \mathrm{~V}$ RHE (or ca. $2.13 \mathrm{~V} v s$. SCE), ${ }^{5}$ as already indicated above.

\section{Conclusions}

The results clearly indicated that the concentration of sulfate in solution is an important parameter during the electrochemical degradation of organic compounds on BDD anode. At low supporting electrolyte concentration, the organic compound molecules were directly degraded on the BDD surface by electron transfer. Meanwhile, when the sulfate concentration was significantly high in the solution $(0.01 \mathrm{M})$, OA degradation occurs through - $\mathrm{OH}$ and persulfate-mediated oxidation. Finally, it is important to mention that these results are partially justified by the theoretical calculations previously reported by Ignaczak et al. ${ }^{11}$ because, in solution, the water molecules prevail close to the anode surface. Also, a lower concentration of the hydroxyl radicals is effectively produced and participates in the oxidation of OA, however, direct oxidation is the main reaction and the theoretical calculations are in line with this mechanism. Nevertheless, the minimum amount of electrolyte should be considered, sulfate or other electrolyte dissolved in water, since the interactions change and the parallel reactions can not be explained by the theoretical calculations, especially when the electrolyte concentration in solution is higher, as demostrated by the Tafel estimations.

\section{Acknowledgments}

Financial support from National Council for Scientific and Technological Development (CNPq; 465571/2014-0, 446846/2014-7 and 401519/2014-7) and FAPESP (2014/50945-4) are gratefully acknowledged. C. A. M.-H. acknowledges the funding provided by the Alexander von Humboldt Foundation (Germany) and Coordenação de Aperfeiçoamento de Pessoal de Nível Superior (Brazil) as a Humboldt fellowship for Experienced Researcher (88881.136108/2017-01) at the Johannes GutenbergUniversität Mainz, Germany. 


\section{References}

1. Martínez-Huitle, C. A.; Panizza, M.; Curr. Opin. Electrochem. 2018, 11, 62.

2. Garcia-Segura, S.; dos Santos, E. V.; Martínez-Huitle, C. A.; Electrochem. Commun. 2015, 59, 52.

3. Michaud, P.-A.; Panizza, M.; Ouattara, L.; Diaco, T.; Foti, G.; Comninellis, C.; J. Appl. Electrochem. 2003, 33, 151.

4. Kapałka, A.; Lanova, B.; Baltruschat, H.; Fóti, G.; Comninellis, C.; Electrochem. Commun. 2008, 10, 1215.

5. Gandini, D.; Mahé, E.; Michaud, P. A.; Haenni, W.; Perret, A.; Comninellis, C.; J. Appl. Electrochem. 2000, 30, 1345.

6. Martínez-Huitle, C. A.; Rodrigo, M. A.; Sirés, I.; Scialdone, O.; Chem. Rev. 2015, 115, 13362.

7. Panizza, M.; Cerisola, G.; Chem. Rev. 2009, 109, 6541.

8. Santos, J. E. L.; Antonio Quiroz, M.; Cerro-Lopez, M.; de Moura, D. C.; Martínez-Huitle, C. A.; New J. Chem. 2018, 42, 5523.

9. Martínez-Huitle, C. A.; Ferro, S.; de Battisti, A.; Electrochim. Acta 2004, 49, 4027.

10. Ferro, S.; Martínez-Huitle, C. A.; de Battisti, A.; J. Appl. Electrochem. 2010, 40, 1779.

11. Ignaczak, A.; Santos, E.; Schmickler, W.; da Costa, T. F.; J. Electroanal. Chem. 2018, 819, 410.

12. Weiss, E.; Groenen-Serrano, K.; Savall, A.; Comninellis, C.; J. Appl. Electrochem. 2007, 37, 41.

13. Scialdone, O.; Galia, A.; Guarisco, C.; Electrocatalysis 2013, 4, 290.

14. Chen, C.; Shyu, S.-F.; Int. J. Quantum Chem. 2000, 76, 541.

15. Buonaugurio, A.; Graham, J.; Buytendyk, A.; Bowen, K. H.; Ryder, M. R.; Keolopile, Z. G.; Haranczyk, M.; Gutowski, M.; J. Chem. Phys. 2014, 140, 221103.

16. Panizza, M.; Cerisola, G.; Appl. Catal., B 2007, 75, 95.

17. Marselli, B.; Garcia-Gomez, J.; Michaud, P.-A.; Rodrigo, M. A.; Comninellis, C.; J. Electrochem. Soc. 2003, 150, D79.

18. Rocha, J. H. B.; Gomes, M. M. S.; Santos, E. V. D.; Moura, E. C. M. D.; Silva, D. R. D.; Quiroz, M. A.; Martínez-Huitle, C. A.; Electrochim. Acta 2014, 140, 419.
19. Davis, J.; Baygents, J. C.; Farrell, J.; Electrochim. Acta 2014, 150,68 .

20. Kapałka, A.; Foti, G.; Comninellis, C.; Electrochem. Commun. 2008, 10, 607.

21. Zhang, C.; He, Z.; Wu, J.; Fub, D.; J. Electrochem. Soc. 2015, 162, E85.

22. Serrano, K.; Michaud, P.; Comninellis, C.; Savall, A.; Electrochim. Acta 2002, 48, 431.

23. Santana, M. H. P.; Faria, L. A. D.; Boodts, J. F. C.; Electrochim. Acta 2005, 50, 2017.

24. Janssen, L. J. J.; Blijlevens, M. H. A.; Electrochim. Acta 2003, 48, 3959.

25. Beck, F.; Krohn, H.; Kaiser, W.; Fryda, M.; Klages, C. P.; Schafer, L.; Electrochim. Acta 1998, 44, 525.

26. Katsuki, N.; Takahashi, E.; Toyoda, M.; Kurosu, T.; Iida, M.; Wakita, S.; Nishiki, Y.; Shimamune, T.; J. Electrochem. Soc. 1998, 145, 2358.

27. Panizza, M.; Cerisola, G.; Electrochim. Acta 2003, 48, 3491.

28. Vogt, H.; Balzer, R. J.; Electrochim. Acta 2005, 50, 2073.

29. Eigeldinger, J.; Vogt, H.; Electrochim. Acta 2000, 45, 4449.

30. Queiroz, J. L. A.; Silva, A. R. L.; Moura, D. C.; Silva, D. R.; Martínez-Huitle, C. A.; J. Electroanal. Chem. 2017, 794, 204.

31. Silva, A. R. L.; Queiroz, J. L. A.; Moura, D. C.; Silva, D. R.; Martínez-Huitle, C. A.; J. Electroanal. Chem. 2017, 794, 93.

32. Brito, C. N.; Ferreira, M. B.; Santos, E. C. M. M.; Léon, J. J. L.; Ganiyu, S. O.; Martínez-Huitle, C. A.; J. Appl. Electrochem. 2018, 48, 1321.

33. de Araújo, D. M.; Sáez, C.; Cañizares, P.; Rodrigo, M. A.; Martínez-Huitle, C. A.; Chemosphere 2018, 207, 774.

34. Araújo, K. C. F.; Barreto, J. P. P.; Cardozo, J. C.; dos Santos, E. V.; de Araújo, D. M.; Martínez-Huitle, C. A.; Environ. Chem. Lett. 2018, 16, 647.

35. Abbar, A. H.; Abbas, A. S.; Port. Electrochim. Acta 2018, 36, 325.

Submitted: August 10, 2018 Published online: March 29, 2019 